\title{
correspondence
}

\section{Alternative refrigerants}

SiR, - We have carried out a survey of possible substitute refrigerants that could be used in the event that it becomes necessary to ban the use of refrigerant-12, $\mathrm{CF}_{2} \mathrm{Cl}_{2}$. Very few compounds meet the requirements of being nontoxic and nonflammable, having long-term stability in a refrigeration system and a short residence time in the lower atmosphere. A good alternative to R-12 must have a normal boiling point near $-30{ }^{\circ} \mathrm{C}$. We have considered all compounds known to boil between -45 and $-15^{\circ} \mathrm{C}$. The list includes approximately 80 compounds of which all but seven can be immediately ruled out as good alternatives. The remaining candidates include $\mathrm{CF}_{3} \mathrm{I}$ (b.p. $=$ $-23^{\circ} \mathrm{C}$ ), $\quad \mathrm{C}_{3} \mathrm{~F}_{8} \quad$ (b.p. $=-36.7^{\circ} \mathrm{C}$ ), c- $\mathrm{C}_{3} \mathrm{~F}_{6} \quad$ (b.p. $=-33^{\circ} \mathrm{C}$ ), $\quad \mathrm{CF}_{3} \mathrm{CH}_{2} \mathrm{~F}$ (b.p. $\left.=-26.5^{\circ} \mathrm{C}\right), \quad c-\mathrm{C}_{3} \mathrm{OF}_{6} \quad$ (b.p. $=$ -29 to $-30^{\circ} \mathrm{C}$ ), $\mathrm{CF}_{3} \mathrm{OC}_{2} \mathrm{~F}_{5}$ (b.p. $=$ $-23.3^{\circ} \mathrm{C}$ ), and $\mathrm{CHF}_{2} \mathrm{Cl}$ (b.p. $=$ $-40.8^{\circ} \mathrm{C}$ ).

Of these compounds $\mathrm{CF}_{3} \mathrm{I}$ may have inadequate long-term thermal stability, decomposing to the products $\mathrm{C}_{2} \mathrm{~F}_{6}$ and $\mathrm{I}_{2}$. We are uncertain as to the flammability of $\mathrm{CF}_{3} \mathrm{CH}_{2} \mathrm{~F}$, and it would be very difficult to prepare this partially fluorinated hydrocarbon in good yield. Perfluoroproprane, $\mathrm{C}_{3} \mathrm{~F}_{8}$, appears to be an ideal refrigerant. We are concerned, however, that this compound would have a much longer atmospheric residence time than R-12 and thus build up to be photolyzed at much longer waveatmosphere. This would be undesirable since it is not possible to predict beforehand all possible environmental effects of a contaminant. Because of the strain energy in perfluorocyclopropane, $c-\mathrm{C}_{3} \mathrm{~F}_{6}$, we expect that this compound to be photolysed at much longer wavelengths than $\mathrm{C}_{3} \mathrm{~F}_{6}$ and thus have a shorter atmospheric residence time. Also, the boiling point of this compound is nearer to that of R-12 and for this reason would be a better substitute. The cyclic ether, perfluoropropylene oxide, and perfluoromethylethyl ether appear to be good substitutes. Presumably, these compounds would rapidly decompose once released into the atmosphere. We are concerned that these compounds may have anaesthetic properties and that they may lack longterm stability in the presence of trace amounts of water. Refrigerant-22, $\mathrm{CHF}_{2} \mathrm{Cl}$, is already used in a wide range of applications. However, its boiling point is much lower than that of R-12 so that its vapor pressure is higher, and thus requires much sturdier and therefore much more expensive refrigeration hardware.

Our civilisation can function without aerosol cans, but not without refrigeration. Except for R-22, any of the alternatives we have suggested would require five to ten years to be produced at the required level. Any decision to ban the use of R-12 should take into account these facts.

JOHN W. BIRKS

THOMAS J. LeCK

School of Chemical Sciences,

University of Illinois,

Urbana, Illinois 61801, USA

\section{Carbon dioxide reduction}

SIR,--As is well-known, the oil crisis raises three distinct technical problems: overall shortage of fuel, shortage of suitable portable fuel (now normally hydrocarbons), and shortage of raw material for organic chemical industry.

Several possible solutions have been advanced for the overall fuel shortage and, if they prove adequate, this should cease to be a problem. If not, we are in a more difficult situation than most of us yet realise.

It has been proposed that the use of hydrogen, readily available with sufficient power, may be an answer to the second problem. For the third no long term answer has been advanced; the use of coal will provide a temporary answer after oil is exhausted, and coal can also be used to produce portable hydrocarbon fuel.

I have already suggested (Nature, 251,469 ) that it is worth looking again at the production of furfural from agricultural waste as a partial, but renewable, answer to the second and third problems.

I do not myself believe that the technology of the liquid hydrogen economy will prove practical on the wide scale, and it seems to me that only organic compounds, though not necessarily hydrocarbons, can provide an answer to the need for a portable fuel.

Thus an answer to both the second and third problems may need a large scale, renewable source of organic compounds. The only inexhaustible source of carbon is carbon dioxide. Given an adequate supply of hydrogen, it is possible to reduce carbon dioxide as is normally done with carbon monoxide in the Fischer Tropsch reaction. It is the purpose of this letter to draw attention to this possibility, and to suggest that the time for basic investigation of this reaction is now, before the need arises.

\section{A. H. TAYLOR}

Department of Chemistry,

University of Natal,

Durban, South Africa

\section{Science and industry}

SiR,-The urgent need for 'Harnessing Science and Industry' in Israel (February 12 , page 442 ) must also apply in the UK. Indeed, discussion is urgently required as to how better use might be made of British scientific innovation and talent, and your leading article (January 29) has done something in this direction by touching upon the possibilities of encouraging more scientists into industry.

But the problem is both deep-seated and urgent. There was a move recently to focus attention on this problem by establishing an exhibit (and perhaps a study centre) in buildings surviving from one of the earliest science-based industries in this country that is, on the site of the historic Perkin and Sons dyeworks at Greenford Green, Middlesex, a mid-nineteenth century enterprise with an enviable record for turning the results of the latest scientific research into technological and commercial success. Ironically, this move failed in January of this year with the deliberate demolition of the buildings of interest due to a lack of appreciation of scientific and technological matters by businessmen and civil-service administrators.

Radlett, Herts., UK

David H. LeabaCK

\section{IQ tests and majority groups}

SiR, - In common usage, and by statute for elections in the USA, "majority" is a number of excess of half the total. In a total with three or more subgroups, the largest is a "plurality". A plurality may also be, but need not be, a majority. I suggest that in Dr Harrington's very valuable study (December 25, page 708), since none of the populations contained a majority, the largest group in each population was a plurality. His results seem to indicate that the more numerous, or principal, groups are favoured by current testing procedures; a most important finding indeed.

Department of Psychology JERRY HIRSCH

University of Illinois,

Champaign, Illinois 61820, USA 